\title{
RESEARCH PAPER \\ Asymmetric yardstick competition: traditional procurement versus public-private partnerships
}

\author{
Giuseppe Di Liddo ${ }^{1}$ - Annalisa Vinella ${ }^{2}$ (D
}

Received: 17 December 2020 / Accepted: 4 June 2021 / Published online: 7 July 2021

(c) The Author(s) 2021

\begin{abstract}
We consider local jurisdictions where rent-seeking administrators undertake identical infrastructure projects, choosing between two contractual arrangements: traditional procurement (TP) and public-private partnership (PPP). A yardstick competition mechanism is triggered through retrospective voters' electoral decisions. A regime with TP in one jurisdiction and PPP in the other is likely to arise when projects are mildly lucrative and/or jurisdictions have moderate fiscal capacity. In this equilibrium, incumbents provide different levels of public services, face different re-election probabilities, and obtain different rents. By differentiating the project governance, incumbents specialize in rent extraction over time, thus hindering yardstick competition although jurisdictions are otherwise identical.
\end{abstract}

Keywords Political yardstick competition · Rent seeking · Local administration · Traditional procurement $\cdot$ Public-private partnership

JEL Classification $\mathrm{H72} \cdot \mathrm{H} 77 \cdot \mathrm{D} 72$

\section{Introduction}

Motivation and aim Administrators of local jurisdictions engaging in electoral contests are subject to yardstick competition, in that voters compare them, taking the level of public services provided in each jurisdiction as a benchmark for evaluation purposes. A relatively good performance in the provision of public services is "rewarded"

Giuseppe Di Liddo

giuseppe.diliddo@uniba.it

Annalisa Vinella

annalisa.vinella@uniba.it

1 Department of Economics, Management and Business Law, University of Bari Aldo Moro, Bari, Italy

2 Department of Economics and Finance, University of Bari Aldo Moro, Bari, Italy 
through a higher probability of the administrator being confirmed in office; a relatively bad performance is "penalized" through a lower probability, instead. In this paper, the yardstick competition mechanism is applied to sub-national contexts in which governments are directly responsible for the development of local infrastructure projects, as is the case in a number of countries (Allain-Dupré 2011). Developing an infrastructure project entails, first, financing and building the infrastructure; next, managing it to provide a service to citizens. To perform these tasks, a form of governance must be chosen. The aim of our study is to investigate the possibility for political incumbents of choosing the project governance strategically to influence the outcome of electoral contests and obtain rents.

The idea of "political yardstick competition" was first formalized by Besley and Case (1995). They offered a political economy model of tax-setting in a multijurisdictional world, which has been further explored in several research pieces thereafter. Those models all represent the fact that voters cannot directly observe the cost of the services provided by the local administrator. Nor can they observe the rent the administrator is able to extract while being in office. To overcome these political agency problems, and be able to decide whether or not to vote again for the incumbent in the next election, citizens compare their own administrator with those in office in other jurisdictions, being based on some observable index of performance, such as the quality/quantity of the provided services. This rests on the common assumption that there exist jurisdictions which are identical or "similar" and can thus be compared. The comparison forces incumbents into a competitive mechanism, in which each incumbent takes the others' behaviour into account to maximize her own rent, considering how the probability of re-election will thereby be affected. To be confirmed in office, incumbents will attempt to make the government they lead well placed in the cross-jurisdiction comparisons made by their respective voters. In this way, although yardstick competition cannot eliminate the informational asymmetry between administrators and voters, it will nonetheless mitigate its consequences.

A number of empirical analyses provide evidence of the existence of a taxmimicking behaviour across local governments. Among others, Besley and Case (1995) find confirmation of this phenomenon using US State data over the period 19601988. In turn, using data about 143 adjacent Italian municipalities, Bordignon et al. (2003) find a positive spatial auto-correlation in local property tax rates in jurisdictions whose mayors run for re-election in uncertain contests. By contrast, no interaction is found in jurisdictions whose mayors face a term limit. In a more recent study, relying on data about German States and local governments, Buettner and von Schwerin (2016) find empirical evidence of the existence of yardstick competition among sub-national jurisdictions in the choice of business tax rates.

Whereas, as we said, most studies have hitherto assumed the existence of identical (or "similar") jurisdictions to be compared, only in recent years some attention has been devoted to the effects that disparities across jurisdictions may have on political yardstick competition. In a theoretical investigation, Allers (2012) highlights that when jurisdictions display fiscal disparities, differing in terms of revenue capacity and/or spending needs, administrators of "richer" jurisdictions can provide high-quality services and still keep the local tax burden low. Thus, whereas they extract high rents, they are also likely to be re-elected. When incumbents do not face the same expected 
rent, given the respective probabilities of re-election, and, hence, the ratio between rents is different from the ratio between probabilities, political yardstick competition is biased. The existence of a bias, due to differences in revenue capacity and/or expenditure needs, seems to be corroborated by the outcome of some recent laboratory experiments (Di Liddo and Morone 2017).

Tax bases and expenditure needs are not the only possible sources of disparities across local jurisdictions. Disparities may also appear when adopting different ways of financing expenditures, leading to different cash flow profiles. This is especially plausible as far as infrastructure projects are concerned, which is the focus of our investigation.

There are two main ways of developing infrastructure projects, namely traditional procurement (henceforth, TP) and the more recent public-private partnership (henceforth, PPP), corresponding to two different organizational forms and financing patterns. Under TP, the construction of the infrastructure and its subsequent management are delegated to different firms through (short-term) contracts. Public funds are disbursed in each phase of the project to cover the cost pertaining to that specific phase, although user charges may also be used to cover the cost of operation when the service is provided. Under PPP, the financing, construction and management of the infrastructure are bundled altogether in a single (longer-term) contract with a consortium of firms, which is transferred the operational risk. Private funds are initially mobilized to finance construction and then recouped during operation. Public funds are disbursed only in this latter stage, and must be set to cover the overall costs of the project, together with user charges (if feasible).

The theoretical literature identifies an efficiency rationale for the use of PPP. That is, if there are any synergies between project phases, then bundling and endogenous risk transfer incentivize the private partner to account for-hence, minimize - the life-cycle costs of the project (Bennett and Iossa 2006; Danau and Vinella 2015, 2017; Hart 2003; Iossa and Martimort 2016; Martimort and Pouyet 2008). However, empirical investigations highlight that politicians may want to use PPP even in the absence of synergies for other reasons. Antellini Russo and Zampino (2010) find that the reliance on PPP is often motivated by purely financial considerations, particularly in local jurisdictions, where public expenditure is subject to tight fiscal rules. ${ }^{1}$ This is because, so long as the International Public Sector Accounting Standard (IPSAS) 32 is not implemented, ${ }^{2}$ under certain circumstances, the involvement of private finance permits to build infrastructures off balance. Actually, according to Engel et al. (2011),

\footnotetext{
1 In recent years, the use of PPP at the local level has proved massive in several countries. For instance, nearly $80 \%$ of the infrastructure projects developed through PPP in Italy over the period 2002-2016, were procured at the municipal level and amounted to more than 33 billion Euros overall (Ufficio Valutazione Impatto. Senato della Repubblica 2018).

2 The IPSAS 32, which is adapted from Interpretation 12 (IFRIC 12), Service Concession Arrangements, developed by the International Financial Reporting Interpretations Committee, and published by the International Accounting Standards Board, sets out the accounting requirements of the grantor in a service concession arrangement. Particularly, it identifies two circumstances under which a grantor should recognize an asset provided by the operator and an upgrade to an existing asset of the grantor as a service concession asset. First, the grantor controls or regulates what services the operator must provide with the asset, to whom it must provide them, and at what price. Second, the grantor controls any significant residual interest in the asset at the end of the term of the arrangement.
} 
this was the ultimate motivation for introducing PPPs in the UK in the first place. Therefore, the claim that the use of PPP relieves public budgets is deceptive, since the official accounting figures hide liabilities, which will appear in future budgets. ${ }^{3}$ That claim is, yet, functional to political opportunism. As suggested by the recent empirical findings in Buso et al. (2017) and Tran and Klien (2017), "kicking the can down the road" may be a convenient strategy for political incumbents wishing to gain support through the undertaking of new investments before elections, without excessively burdening the yearly budget accounting.

These empirical findings all point to the conclusion that the ways in which public projects are financed and developed may (and often do) serve strategic purposes in political contests. However, to the best of our knowledge, the literature has not yet explored how political yardstick competition may be affected thereby.

The goal of our study is to investigate how the choice of developing infrastructure projects by means of either TP or PPP impacts on yardstick competition among nonbenevolent (rent-seeking) administrators, shedding light on the incentives which lead them to prefer one or the other form of project governance. To pursue that goal, we innovate on previous studies on political yardstick competition in three main respects. First, rather than focusing on fiscal disparities across jurisdictions, the impact of which is known from the literature, we concentrate on disparities associated with different disbursement patterns. Second, we allow for the disparities to result from the decisions made by the administrators, rather than taking them as being exogenous in line with Allers (2012). Third, precisely because disparities are endogenous in our model, we can account for the possibility of using them deliberately as a strategic tool to influence the yardstick competition outcome and appropriate higher rents. With this approach, we also contribute to the literature on public procurement, in that we reconsider the TP/PPP dichotomy from an institutional perspective, nesting the choice of the contractual arrangement in the strategic interactions among (local) governments, rather than insisting on budgetary reasons along the lines of previous research.

Setting and results We construct a theoretical model representing two identical jurisdictions over a time horizon of two periods, capturing the usual municipal term limit in a variety of institutional settings (e.g., Italy, the US). In either jurisdiction, the administrator in office delegates the development of a public project to the private sector under either TP or PPP. In the first period, the infrastructure is built and new elections take place; in the second period, the infrastructure is managed to provide a new service to citizens. Each incumbent aims at extracting the highest attainable rent, taking into account the other incumbent's behaviour and the impact on the probability of re-election. As in Kotsogiannis and Schwager (2008), voters are uninformed of the cost of services and do not observe the rent-seeking behaviour of the incumbent of their jurisdiction. Hence, they assess her performance being based on the supplies of public services in both jurisdictions. An incumbent providing poorer services will see her jurisdiction fare worse in this comparison and her chances of re-election will decrease.

\footnotetext{
3 Maskin and Tirole (2008) point out that one of the reasons why the involvement of private finance is beneficial is that, by certifying the costs of the projects publicly, it permits to securitize the associated public sector liabilities. However, this would require recording those liabilities correctly in the public budgets.
} 
As a first step of the analysis, we characterize the equilibrium payoffs of the incumbents for given forms of the project governance. On the one hand, when the same form of governance is used in the two jurisdictions, yardstick competition leads to a symmetric equilibrium. In this kind of situations, when local voters observe that the local expenditure in their own jurisdiction is higher than that in the neighbour jurisdiction, they think that the performance of their own administrator is superior to that of her counterpart in the other jurisdiction. As long as local incumbents use the same project governance, the local expenditure provides a true picture of their performance. It follows that incumbents devote the same amount of expenditure for service provision, face the same probability of running a new mandate, and extract the same rent from office. It means that political yardstick competition is effective when incumbents use either both PPP or both TP. On the other hand, when different forms of governance are used in the two jurisdictions, an asymmetric equilibrium arises. In this case, the different inter-temporal allocation of project disbursements makes local expenditure a biased proxy of the incumbents' true performance. As a consequence, incumbents set different expenditure levels, and face different probabilities of re-election and rents. Unlike in the previous case, with the ratio between probabilities differing from the ratio between rents, political yardstick competition is found to be biased. The bias is especially pronounced if big investments are made and/or the interest rate on capital is high.

Among these possible equilibria, we identify the one to actually arise, by endogenising the choice of the project governance, and abstracting from any differences in cost of operation between TP and PPP. That is, PPP does not grant any cost savings in management, hence it is not justified on efficiency grounds. Hence, there is no other source of disparity between jurisdictions than the timing of outlays associated with the project. Under this circumstance, the choice between TP and PPP is determined exclusively by the incumbents' rent-seeking behaviour. Considering jurisdictions with retrospective voters displaying a myopic attitude, we identify essentially two situations in which one should be concerned with the strategic use of PPP, absent any efficiency reasons (synergies between project phases). First, when projects are highly lucrativeas often in energy and transportation sectors - and/or jurisdictions have a substantial capability of raising resources through taxation, PPP is a better rent-extraction tool for either incumbent. Second, when projects are mildly lucrative-as plausible with sport arenas and other entertainment facilities - and/or jurisdictions have a moderate capability of raising taxes, the incumbents find it convenient to differentiate their strategies to appropriate surplus. Accordingly, one relies on TP, the other opts for PPP. Importantly, whereas with symmetric strategies political yardstick competition is effective, with asymmetric strategies it is hindered instead. Indeed, by choosing different contractual arrangements to develop the public project, the incumbents are able to weaken the competitive pressure, specialising as rent-takers over time.

Outline The remainder of the paper is organized as follows. In Sect. 2 we describe the model. In Sect. 3 we first examine the cases where both incumbents use either TP or PPP. We next explore situations in which different financing forms are adopted in the two jurisdictions. In Sect. 4 we identify and discuss the equilibria which can actually be expected to arise in the strategic game between local incumbents. Section 5 
concludes and proposes alleys to further research. Mathematical details are relegated to an appendix.

\section{The model}

We consider two identical jurisdictions, $A$ and $B$, with identical voters and population, whose size is normalized to the unity. We assume that, as in a number of local electoral systems, such as the UK districts and the Italian municipalities, incumbents can be in office for a maximum of two mandates. To represent this time horizon, we consider two periods, denoted 1 and 2 . In period 1 both administrators run their first mandate. At the end of period 1 an election takes place for a mandate to be run in period 2. Given the term limit, if an administrator is re-elected, then her second mandate will be the last one.

In jurisdiction $i \in\{A, B\}$ an expenditure of $E_{i, t}$ is incurred to provide public services in period $t \in\{1,2\}$. This can be viewed as a measure of the level (or quality) of public services, with the minimum normalized to zero. ${ }^{4}$ To fund the cost of provision of public services, a tax is levied on the exogenously determined tax base $\Theta$ at a rate of $\tau$, which is set by the central government. The total tax revenue is thus $\Upsilon=\tau \Theta$ in either jurisdiction.

Infrastructure project: governance and financial profile In the two jurisdictions an (identical) infrastructure project is undertaken and developed through the two periods. In period 1 an infrastructure that costs $K \in(0, \Upsilon]$ is built (the construction phase). In period 2 the infrastructure is used to provide an additional service to the population (the operation phase). Prior to construction, each administrator chooses the governance (i.e., the financial and organizational form) of the project. Two options are available, namely TP and PPP. Contracts are signed with private operators according to the selected option.

Under TP, each phase of the project is delegated to a different operator. A construction contract is signed with the infrastructure builder at the beginning of period 1. A service contract is signed with the service provider at the beginning of period 2 , and takes into account that the provider will sustain a cost of operation equal to $C_{T}$ in period 2. Under this contractual arrangement, the pattern of disbursements to the jurisdiction coincides with the pattern of costs sustained for the project. In compliance with the construction contract and the service contract respectively, the administrator makes a payment of $K$ to the infrastructure builder, and a payment of $C_{T}$ to the service provider. In turn, she receives user fees of $F_{T}$ from the service provider, who collects them in the market.

Under PPP, the two phases of the project are bundled together and delegated to a single operator. A construction-and-service contract is signed with the private partner at the beginning of period 1 . This is an incentive contract, which also establishes an efficient allocation of the risks of the project. With this, bundling induces the operator to account for all the costs over the whole life-cycle of the project. Hence, unlike under

\footnotetext{
${ }^{4}$ A level (or quality) of services equal to zero indicates that only basic services are provided, whereas a strictly positive level indicates that more sophisticated services are provided.
} 
Table 1 Summary of assumptions on TP and PPP

\begin{tabular}{lll}
\hline & TP & PPP \\
\hline Period 1 & & \\
Contract & Construction & Construction + service \\
Private party & Constructor & Operator \\
Cost of construction & $K$ & $K$ \\
Public disbursement & $K$ & - \\
Fees & - & - \\
Period 2 & & - \\
Contract & Service & Operator \\
Private party & Provider & $C_{P}$ \\
Cost of operation & $C_{T}$ & $(1+r) K+C_{P}$ \\
Public disbursement & $C_{T}$ & $F_{P}$ \\
Fees & $F_{T}$ &
\end{tabular}

TP, if there are externalities between project phases, then the operator internalizes them. Accordingly, the cost of operation $C_{P}$ will be below $C_{T}$ if the externalities are positive, in which case internalization is desirable and PPP is an appropriate regime, on an efficiency ground. Given that our aim is to study political yardstick competition, in order to keep the analysis well focused, we do not represent the risks of the project and their contractual allocation explicitly, and only capture the ultimate effect of the contract through the fact that internalization of the externalities results in a lower cost of operation. If externalities are either negative or absent, then $C_{P} \geq C_{T}$, and there is no efficiency motivation for employing PPP. ${ }^{5}$

Unlike under TP, the pattern of disbursements to the jurisdiction now diverges from the pattern of costs sustained for the project. Indeed, according to the PPP contract, the cost of construction $K$ is initially financed by the private operator and then recouped during the operation phase. As a result, the cost of construction burdens the jurisdiction only in period 2. However, at that time, it amounts to $(1+r) K$, where $r \in(0,1)$ is the interest rate. Besides, in period 2 the administrator also receives the revenues $F_{P}$, which the private partner collects in the market. ${ }^{6}$

For clarity, we summarize assumptions on TP and PPP in Table 1.

\footnotetext{
5 PPP is a longer-term and more complex contractual arrangement than TP. On the one hand, a long contractual duration shields the private operator from the competitive pressure and may trigger inefficiencies over time. Furthermore, there is a risk that the public partner remains locked in obsolete contractual terms, while user preferences change during the execution of those terms. On the other hand, a more complex contract is more difficult (and costly) to enforce and monitor. Although we avoid capturing these aspects formally to keep our model well focused, they all provide (potential) reasons for not adopting PPP to develop infrastructure projects that do not display any synergies between phases (i.e., with $C_{P} \geq C_{T}$ ).

${ }^{6}$ The practice of returning the user fees collected by the private company to the public partner is common in PPP projects as well. For instance, this was the case of the Vélib' project launched in Paris in 2007 to offer citizens a bicycle-sharing scheme. As Iossa and Saussier (2018) point out, although the Vélib' contract stipulated by the City of Paris with the private partner JC Decaux was officially a TP contract, it was tantamount to a PPP contract on technical grounds.
} 
To develop the analysis, we will focus on situations in which the user fees of the additional service collected in period 2 are the same, regardless of the form of governance adopted for the project: $F_{T}=F_{P}=F$. Although this restriction is not essential for our results, ${ }^{7}$ it permits to rule out any disparity in revenue capacity between jurisdictions, the impact of which is known from previous research, and isolate the effect of the outlays of the project on the outcome of political yardstick competition, which is novel to our study. Nonetheless, the assumption of equal and exogenously set fees appears to be realistic in a number of cases. For instance, equal fees apply if the service is subject to some form of price regulation by an independent authority, say, in the energy or transportation sector. They may also result from the use of standardized contracts for the development of infrastructure services with homogeneous characteristics. ${ }^{8,9}$ Noticeably, our formalization also encompasses the limit case where $F=0$, representing private finance initiative (or availability-based) projects which, unlike concessions, are incapable of generating market revenues. Then, the main buyer is the public administration, and the private firm is exclusively remunerated through public payments. Henceforth, we will let $\Gamma \equiv \Upsilon+F$ denote the total second-period revenues in either jurisdiction, where $F \geq 0$.

Administrators and voters Each administrator acts as a pure rent-seeker. In period 1 she attempts to maximize the rent she can obtain over the two-periods horizon. This requires taking into account that a second mandate, to be run in period 2 , will be obtained only with some probability, which will depend on the voters' appreciation. To represent the voters' behaviour, we do not model preferences through a utility function, and only take preferences to be homogeneous between jurisdictions. In line with the literature on political yardstick competition, we assume that voters take a purely retrospective behaviour. In each jurisdiction, they decide whether or not to vote again for the incumbent, being based on the outputs of the administration decisions made in the two jurisdictions, which they can observe and compare. In other words, they assess the performance of one administrator relative to that of the other, using observable outcomes as a proxy for the effort the administrators exert. Essentially, these outcomes are the levels of public services provided in period 1, as measured by $E_{A, 1}$ and $E_{B, 1}$.

Actually, there are two more things which voters observe in period 1. However, none of them is useful for comparisons. First, voters observe the tax rates, according to which local taxes are levied; local taxation is exogenous and equal in the two jurisdictions though. Second, voters observe that an infrastructure has been built for

\footnotetext{
7 Calculations with different market revenues in the two jurisdictions are available with the authors.

8 Standardized contracts are largely relied upon in the UK to boost the transparency of the awarding process and the accountability of public officials (HM Treasury 2006). They are considered to be especially useful as far as local governments are concerned. Indeed, on the one hand, local governments have a limited expertise in the use of complex procurement mechanisms. On the other hand, they are particularly exposed to opportunism and corruption (see Iossa and Martimort 2016, for instance).

9 There are also other reasons why the fees are not (fully) in the administrators' choice. In many instances, procurement contracts are tendered out and the fees are determined through the auction mechanism, given the market conditions. Moreover, even if the contract is awarded through a negotiation with the firm, in which the public authority has much bargaining power, the determination of the fees cannot abstract from considerations about the firm's willingness to participate and incentives to behave virtuously, the representation of which is beyond the scope of this study.
} 
future use in either jurisdiction, under a given contractual arrangement. Nonetheless, whereas the project is identical in the two jurisdictions, voters do not yet know its outcome, namely, the service to be available in a later stage. Nor are voters informed of how the costs of the project will differ under the two contractual arrangements. Hence, the particular choice of one or the other arrangement is irrelevant to them. Beyond a generic desire for having administrators do the "right thing," voters need to wait until after they will have observed outputs (services) to be able to form an assessment of the project. ${ }^{10}$ This behaviour mirrors the argument, put forward by Allers (2012), that yardstick competition is a simple tool used by unsophisticated voters, who typically do not have enough economic expertise to judge over such complex issues as the choice of the suitable contractual arrangement. If voters were able to assess contractual alternatives, then, plausibly, they would also be able to read budgets, estimate cost curves, and deduce rents. Yardstick competition itself would become useless in that case. ${ }^{11}$ Thus, in definitive, the probability of re-election depends only on $E_{A, 1}$ and $E_{B, 1}$ for either incumbent.

Probability of re-election To represent the probability of re-election, we follow the contest success function (CSF) approach, in line with a number of existing studies on political yardstick competition and related topics (Bodenstein and Ursprung 2005; Cole et al. 2018; Huang and He 2021; Klumpp et al. 2019; Long 2013; Pastine and Pastine 2012; Tullock 1980). This reduced-form, simple contest approach is convenient in that it permits to capture the basic relationship between voters' behaviour and rent-seekers' policy choices, yet, abstracting from the specific institutional setting and agents' preferences (Epstein and Nitzan 2006). Following this approach, we can thus represent the political contest without making any specific assumptions on local preferences, as we said. Formally, the CSF is given by

$$
\rho_{i}\left(E_{i, 1}, E_{j, 1}\right)=\frac{E_{i, 1}}{E_{i, 1}+E_{j, 1}}, \forall i \neq j \in\{A, B\},
$$

and respect two natural properties. First, it is increasing and concave in the expenditure for services made in the own jurisdiction, whereas it is decreasing in the expenditure made in the rival jurisdiction. Second, the probability boils down to $1 / 2$ when the incumbents behave exactly in the same manner in the two jurisdictions $\left(E_{i, 1}=E_{j, 1}\right)$.

\footnotetext{
10 With PPP, because the contract is stipulated at the beginning of period 1 , the fees of the service to be supplied in period 2 are also known in the first period. The same occurs with TP, if the fees are exogenously set (or there are no fees at all), as here considered. Otherwise, with TP the fees would only be known in period 2, when the service contract is signed. Consider this latter situation, for a moment. Of course, whereas an administrator who chooses PPP can advertise the price information among voters in period 1, an administrator who chooses TP cannot afford to do that. Nonetheless, even where the price information is available, there is not much use in learning it, as long as voters cannot see what that price is for. One may object that early availability of the price of a future service would be per se a good signal of the concerned administrator relative to her competitor. In fact, this is not necessarily the case. Indeed, it is equally plausible that voters would dislike current politicians to commit to policies restraining future administrators' choices. ${ }^{11}$ Likewise, in the words of Cunha Marques and Berg (2011), "those bearing the costs (customers) are diffuse and lack information regarding relative performance under alternative arrangements." (p.1602).
} 
Thus, under the yardstick mechanism, the incumbent who provides better services, which signal more effort, gains consensus; the other looses it. ${ }^{12}$

Timing of the game To summarize, the game the administrator plays in each jurisdiction $i$ unfolds as follows.

At the beginning of period 1, the administrator chooses the governance of the infrastructure project (either TP or PPP) and sets the level of expenditure $E_{i, 1}$.

During period 1:

- Under TP and PPP respectively, the administrator signs the construction contract and the service-and-construction contract with a private firm.

- The firm sinks a cost of $K$ to build the infrastructure.

- Under TP the administrator reimburses the cost $\mathrm{K}$ to the firm.

- The administrator disburses $E_{i, 1}$ for public service provision, which citizens observe together with $E_{j, 1}$.

At the end of period 1, voters cast a vote in the poll and the incumbent administrator is re-elected with a probability of $\rho_{i}$.

At the beginning of period 2, the administrator sets the level of expenditure $E_{i, 2}$.

During period 2:

- Under TP, the administrator currently in office signs a service contract with a private firm.

- Under TP and PPP respectively, the firm sustains a cost of $C_{T}$ and $C_{P}$ to provide the service to citizens.

- Under TP and PPP respectively, the administrator reimburses the costs $C_{T}$ and $(1+r) K+C_{P}$ to the firm, and receives the revenues $F_{T}$ and $F_{P}$.

- The administrator disburses $E_{i, 2}$ for public service provision, which citizens observe together with $E_{j, 2}$.

\section{Characterization of the equilibria}

We are now ready to characterize the non-cooperative equilibria of the game between incumbents. After considering a case where both jurisdictions rely on TP, denominated TT regime, we turn to explore a case where both jurisdictions rely on PPP, denominated $P P$ regime. Although these two cases are similar, we present them separately to make it clear how they differ in terms of inter-temporal disbursement profiles. We complete this part of the analysis with the description of a "mixed" case where TP is used in one jurisdiction and PPP in the other. This will be referred to as the T/P regime. Regardless of the regime, we will conclude that yardstick competition is effective if the

$12 \mathrm{~A}$ more general formulation of the $\mathrm{CSF}$ would be $\rho_{i}\left(E_{i, 1}, E_{j, 1}\right)=$ $f_{i}\left(E_{i, 1}\right) /\left(s+f_{i}\left(E_{i, 1}\right)+f_{j}\left(E_{j, 1}\right)\right)$, where $f_{i}(\cdot)$ and $f_{j}(\cdot)$ are non-negative strictly increasing functions, and $s>0$ is a constant term (Jia et al. 2013). Within the class of specifications employed in the economics of rent-seeking and contests, the one we use neatly represents the negative correlation between the incumbents' probabilities of re-election. Although this entails the somewhat extreme result that the probabilities of re-election always sum up to one, the advantage is that it ensures that the total amount of resources, which could be extracted under the form of rents over the two jurisdictions, does not depend on the effort exerted by the local incumbents, and remains fixed in all considered regimes, thus making the comparison between symmetric and asymmetric cases more significant. 
ratio between probabilities of re-election is found to equal the ratio between expected rents. We will conclude that yardstick competition is biased if the two ratios are found to be different instead.

\subsection{The TT regime}

Suppose that TP is used in both jurisdictions. Under TP each phase of the project is delegated to a different operator so that, if there are externalities between phases of the project, then they are not internalized. Accordingly, the expected value of the rent of the incumbent in jurisdiction $i \in\{A, B\}$ is given by

$$
R_{i}\left(E_{i, 1}, E_{i, 2}, E_{j, 1}\right)=\Upsilon-E_{i, 1}-K+\beta \rho_{i}\left(E_{i, 1}, E_{j, 1}\right)\left(\Gamma-E_{i, 2}-C_{T}\right),
$$

where $\beta \in[0,1]$ is the discount factor. In period 1 the rent is given by the tax revenues less the expenditure in public services and the cost of investment in the new infrastructure. In period 2 the rent (to be obtained only in case of re-election) includes the tax revenues less the expenditure in public services and, in addition, the market revenues of the new service less the cost of supplying the service. The administrator of jurisdiction $i$ chooses the levels of expenditure $E_{i, 1}$ and $E_{i, 2}$ in such a way as to attain the highest expected rent. ${ }^{13}$

Because the rent decreases with $E_{i, 2}$ and the incumbent has no electoral concerns in period 2, she is aware that there will be no point in setting $E_{i, 2}$ above the minimum at the beginning of period 2. Hence, $E_{i, 2}^{T T}=0$, where the superscript $T T$ denotes the regime here considered. One may wonder why voters should be based on previous expenditure choices when deciding whether or not to confirm the incumbent at the end of period 1, given that such choices will end up not being actually indicative of how the incumbent would behave in period 2, if confirmed in office. In fact, this is consistent with the real-world evidence, well-documented in a number of Political Science studies, that retrospective voters tend to display a myopic attitude. They make their electoral decisions being based on the observation of past behaviour, even if that behaviour is poorly informative about future performance, simply because they find it difficult to form reliable forecasts about what a political challenger would do. Thus, rather than looking over the full duration of a government office, they prefer to stick to what they experienced prior to casting their ballot. ${ }^{14}$ Obviously, if voters are

\footnotetext{
13 The budget surplus can also be used to favour special interest groups (say, in the form of campaign contributions) in the hope of acquiring political support. Our model could easily be extended to allow for this kind of rent conversion (laundering). Therefore, the applicability of our analysis is wider than the formal representation seems to suggest.

14 There is evidence that this attitude is typical, in particular, of US voters, who tend to view elections as a referendum on the past performance of a (possibly term-limited) officeholder. As the political scientist V.O. Key Jr. points out in his by now classic book "The Responsible Electorate", judging an incumbent's performance in office represents a perfect opportunity for voters to play "rational God of vengeance or reward." See also Fiorina (1981), Healy and Lenz (2014) and Huber et al. (2012). Achen and Bartels (2016) argue that retrospective voting is often causally unsophisticated and ideologically confused. Healy and Malhotra (2013) point out that voters resemble decision makers in many other domains. That is, whereas a coherent logic governs their choices in a number of instances, in others they are hardly able to process all the relevant information and subject to psychological biases.
} 
short-sighted, then incumbents are motivated to care about their opinion only before running for a re-election, and are prone to shirk as any electoral concerns disappear. This is all the more true that interactions (hence, comparisons) with administrators in other jurisdictions are reduced (or vanish) when incumbents are in their last term of office, entailing that they are not sensitive to neighbours' behaviour when they are not allowed to run for re-election (Besley and Coate 1995).

With $E_{i, 2}^{T T}=0$, we can save on notation and drop the time index from the levels of expenditure in period 1. Accordingly, the incumbent's problem boils down to choosing $E_{i}$ to maximize

$$
R_{i}\left(E_{i}, E_{j}\right)=\Upsilon-E_{i}-K+\frac{\beta E_{i}}{E_{i}+E_{j}}\left(\Gamma-C_{T}\right) .
$$

Inspection of (1) highlights that the incumbent faces a trade-off in the choice of $E_{i}$. Whereas more expenditure reduces the rent in period 1 , it makes it more likely that further surplus will be retained through a second mandate. The best is to set $E_{i}$ such that the marginal loss in period 1 equals the marginal expected benefit in period 2 , according to the following rule: ${ }^{15}$

$$
1=\frac{\beta E_{j}}{\left(E_{i}+E_{j}\right)^{2}}\left(\Gamma-C_{T}\right) .
$$

This condition can be used to derive a more explicit formulation of $E_{i}$, given the expenditure choice made in the competing jurisdiction, namely ${ }^{16}$

$$
E_{i}\left(E_{j}\right)=\sqrt{\beta\left(\Gamma-C_{T}\right) E_{j}}-E_{j} .
$$

Considering that this is true, mutatis mutandis, for administrator $j \neq i$ as well, one can pin down the equilibrium levels of expenditure and, hence, the resulting probabilities of re-election and expected rents. As jurisdictions are homogeneous in any respect, the equilibrium is symmetric, and we can write the equilibrium values dropping subscripts for simplicity: ${ }^{17}$

$$
E^{T T}=\frac{\beta}{4}\left(\Gamma-C_{T}\right)
$$

\footnotetext{
15 The concavity of this and the next optimization problems are verified in appendix.

16 All throughout, we assume that $\Gamma-C_{T}>0$, entailing that no budget deficit is induced to have the project developed. This assumption might be thought of as reflecting the existence of any legal or constitutional budget-balancing requirements at the sub-national government level. For instance, in Italy such a requirement was introduced by Law n. 2012/243 to implement the budget-balancing principle stated in article 81 of the Italian Constitution (as modified by Constitutional Law n. 2012/1).

17 As usual in this kind of games (see Di Liddo and Giuranno 2016, among others), in addition to the solution presented in the text, there is also a corner solution. In the resulting equilibrium, the yardstick mechanism fails to motivate the incumbents to exert any effort, and they both provide the minimum level of public services $\left(E_{i}=0, \forall i\right)$, facing a re-election probability of $1 / 2$ and extracting the maximum available rent, which amounts to $\Upsilon-K+\beta\left(\Gamma-C_{T}\right) / 2$. We do not insist on equilibria of this sort as that would not enrich the insights of our study.
} 


$$
\begin{aligned}
\rho^{T T} & =\frac{1}{2} \\
R^{T T} & =\Upsilon-K+\frac{\beta}{4}\left(\Gamma-C_{T}\right) .
\end{aligned}
$$

First, not surprisingly, yardstick competition is effective in the absence of disparities. Second, a unitary increase in $K$ leads to a unitary reduction in the extracted rent, whereas it leaves the level of services unaltered. Intuitively, an incumbent cannot afford downgrading public services to pass (a part of) the cost of investment onto citizens. Indeed, that choice would decrease her chance to be in office in period 2. Yet, under TP, it is precisely in period 2 that the incumbent can extract more surplus, provided the entire cost of investment was sustained in period 1.

\subsection{The PP regime}

Suppose that PPP is adopted in both jurisdictions. Under PPP the two phases of the project are delegated to a single operator, who invests up-front to build the infrastructure and internalizes the externalities between phases of the project, if any. Accordingly, the expected value of the rent of the incumbent in jurisdiction $i \in\{A, B\}$ amounts to

$$
R_{i}\left(E_{i, 1}, E_{i, 2}, E_{j, 1}\right)=\Upsilon-E_{i, 1}+\beta \rho_{i}\left(E_{i, 1}, E_{j, 1}\right)\left(\Gamma-E_{i, 2}-(1+r) K-C_{P}\right),
$$

In period 1 the rent is now given by the tax revenues net of the sole expenditure in public services. In period 2 the rent embodies, first, the tax revenues net of the expenditure in public services; it also embodies the market revenues of the new service net of the total cost of building and managing the infrastructure for supply, which includes the interests on capital. With analogous explanation to the TT regime, there is no point for the administrator in setting the expenditure above the minimum level in the second period so that $E_{i, 2}^{P P}=0, \forall i \in\{A, B\}$, where the superscript $P P$ denotes the regime here considered. Dropping again the time index, the incumbent's problem boils down to choosing $E_{i}$ in such a way as to maximize

$$
R_{i}\left(E_{i}, E_{j}\right)=\Upsilon-E_{i}+\frac{\beta E_{i}}{E_{i}+E_{j}}\left(\Gamma-(1+r) K-C_{P}\right)
$$

As under TP, the incumbent faces a trade-off in the choice of $E_{i}$, which is now captured through the following optimization rule:

$$
1=\frac{\beta E_{j}}{\left(E_{i}+E_{j}\right)^{2}}\left(\Gamma-(1+r) K-C_{P}\right)
$$


Accordingly, $E_{i}$ can be further expressed as a function of the expenditure choice in the competing jurisdiction, namely ${ }^{18}$

$$
E_{i}\left(E_{j}\right)=\sqrt{\beta\left(\Gamma-(1+r) K-C_{P}\right) E_{j}}-E_{j} .
$$

Considering that this is true, mutatis mutandis, for administrator $j \neq i$ as well, the levels of expenditure, the probabilities of re-election and the expected rents in equilibrium are determined as follows:

$$
\begin{aligned}
E^{P P} & =\frac{\beta}{4}\left(\Gamma-(1+r) K-C_{P}\right) \\
\rho^{P P} & =\frac{1}{2} \\
R^{P P} & =\Upsilon+\frac{\beta}{4}\left(\Gamma-(1+r) K-C_{P}\right),
\end{aligned}
$$

where again we have dropped the subscript denoting the jurisdiction since the equilibrium is symmetric. ${ }^{19}$ First, as usual in the absence of disparities, yardstick competition is effective exactly as in the TT regime. Second, in the PP equilibrium, not only does a unitary increase in $K$ trigger a reduction of $\beta(1+r) / 4$ in the expected rent. It also triggers an equal reduction in the level of services, which was found to remain unaltered under TT instead. Moreover, because $(\beta(1+r) / 4)<1$, the rent reduction is lower in the PP regime than in the TT regime. Intuitively, when PPP is used the cost of investment generates a public disbursement in period 2, which reduces the surplus an administrator can appropriate in that period. Because of this, incumbents care less of a second mandate, and are thus less concerned with downgrading public services in period 1 in order to pass a part of the cost of investment onto citizens. In definitive, whereas the cost of investment only burdens the incumbents under TT, it is shared with the citizens in the PP regime. As a result, citizens receive a lower level of services under PP than under TT $\left(E^{P P}<E^{T T}\right)$, unless TP is significantly less efficient in operation than PPP $\left(C_{T}-C_{P}>(1+r) K\right)$. Clearly, this entails that, in a case where TP and PPP are equally efficient in operation $\left(C_{T}=C_{P}\right)$, in period 1 citizens receive better services under TT than under PP.

\subsection{The T/P regime}

Suppose that the project is developed by means of TP in one jurisdiction and PPP in the other. To avoid confusion, we will append the subscript $T$ to indicate the former jurisdiction and the subscript $P$ to indicate the latter, instead of the subscripts $i$ and $j$ previously used.

\footnotetext{
18 For the same reason as in the TT regime, we assume that $\Gamma-(1+r) K-C_{P}>0$.

19 As in the TT regime, in addition to the solution presented in the text, there is also a corner solution of the game, namely, an equilibrium in which both incumbents provide the minimum level of public services, face a re-election probability of $1 / 2$, and extract the maximum rent, which is equal to $\Upsilon+$ $\beta\left(\Gamma-(1+r) K-C_{P}\right) / 2$.
} 
In jurisdiction $T$ the expected rent is as presented in (1), hence the incumbent's reaction function is given by (3), where now $i=T$ and $j=P$. Likewise, in jurisdiction $P$ the expected rent is as presented in (7), hence the incumbent's reaction function is given by (9), with the same adapted notation. Using (3) together with (9), one derives the levels of expenditure, the probabilities of re-election and the expected rents in the T/P equilibrium. ${ }^{20}$ Denoting $C \equiv C_{T}+C_{P}$ for shortness, they are respectively given by

$$
\begin{aligned}
& E_{T}^{T / P}=\beta \frac{\left(\Gamma-(1+r) K-C_{P}\right)\left(\Gamma-C_{T}\right)^{2}}{(2 \Gamma-(1+r) K-C)^{2}} \\
& E_{P}^{T / P}=\beta \frac{\left(\Gamma-C_{T}\right)\left(\Gamma-(1+r) K-C_{P}\right)^{2}}{(2 \Gamma-(1+r) K-C)^{2}}
\end{aligned}
$$

and

$$
\begin{aligned}
\rho_{T}^{T / P} & =\frac{\Gamma-C_{T}}{2 \Gamma-(1+r) K-C} \\
\rho_{P}^{T / P} & =\frac{\Gamma-(1+r) K-C_{P}}{2 \Gamma-(1+r) K-C}
\end{aligned}
$$

and

$$
\begin{aligned}
& R_{T}^{T / P}=\Upsilon-K+\beta \frac{\left(\Gamma-C_{T}\right)^{3}}{(2 \Gamma-(1+r) K-C)^{2}} \\
& R_{P}^{T / P}=\Upsilon+\beta \frac{\left(\Gamma-(1+r) K-C_{P}\right)^{3}}{(2 \Gamma-(1+r) K-C)^{2}}
\end{aligned}
$$

It is straightforward to see that, whereas the ratio between probabilities of re-election equals that between levels of expenditure, it differs from the ratio between expected rents, in general. This entails that political yardstick competition is unlikely to be effective in the mixed regime.

There is an important novel aspect to the T/P regime relative to TT and PP. There are two (potential) sources of disparities associated with the two different forms of project governance, namely the cost of operation (if synergies between project phases are present) and the inter-temporal disbursement profile. Inspecting (13a)-(15b), we see that $E_{T}^{T / P}>E_{P}^{T / P}$ together with $\rho_{T}^{T / P}>\rho_{P}^{T / P}$ if and only if $(1+r) K>C_{T}-$ $C_{P}$, that is, TP is not particularly inefficient relative to PPP, and/or the disbursement associated with the cost of investment is sufficiently high under PPP. With projects of this kind, the expected rent may be lower with PPP because there is not much that can

\footnotetext{
20 As in the TT and PP regimes, in addition to the solution presented in the text, there is also a corner solution such that both incumbents provide the minimum level of public services and are re-elected with probability Footnote 20 continued

of $1 / 2$. Furthermore, each of them extracts the maximum rent, given $F$. Specifically, the rent of administrator $T$ amounts to $\Upsilon-K+\beta\left(\Gamma-C_{T}\right) / 2$, that of administrator $P$ amounts to $\Upsilon+\beta\left(\Gamma-(1+r) K-C_{P}\right) / 2$.
} 
be saved in cost of management, and/or there is much to repay in terms of capital in period 2. Under these circumstances, yardstick competition is biased. ${ }^{21}$

\section{What are the relevant equilibria?}

We now turn to establish which of the explored regimes will actually arise, hence what equilibria are relevant. This will enable us to understand whether and under what conditions incumbents should be expected to make a strategic use of the financing form of the project. To that end, we will compare the incumbents' rents across regimes and identify the regime under which they are highest. That is the regime for which the incumbents will opt.

We restrict attention to a case where the cost of operation with TP is equal to that with PPP so that, absent any savings in cost of operation, PPP should not be preferred to TP. This focus is functional to the purpose of our analysis. Indeed, once any considerations on the disparity in cost of operation are net out, the choice of a specific form of governance will mirror only strategic motivations associated with the inter-temporal disbursement profile. We will see that equilibria with PPP being utilized do emerge, in fact.

Formally, we assume that $C_{P}=C_{T}=C / 2$ regardless of the regime. Further letting $X \equiv 2 \Gamma-C$ for shortness, we can write the rents in the TT and PP regime as

$$
R^{T T}=\Upsilon-K+\frac{\beta}{8} X \text { and } R^{P P}=\Upsilon+\frac{\beta}{8}(X-2(1+r) K)
$$

It is immediate to verify that $R^{T T}<R^{P P}$ since $\beta(1+r)<4$. Moreover, the rents in the $\mathrm{T} / \mathrm{P}$ regime are specified as

$$
R_{T}^{T / P}=\Upsilon-K+\frac{\beta}{8} \frac{X^{3}}{(X-(1+r) K)^{2}} \quad \text { and } \quad R_{P}^{T / P}=\Upsilon+\frac{\beta}{8} \frac{(X-2(1+r) K)^{3}}{(X-(1+r) K)^{2}}
$$

The four regimes to be considered are one TT regime, in which both incumbents opt for TP; one PP regime, in which both incumbents opt for PPP; and two T/P regimes, in which one incumbent opts for TP and the other opts for PPP. To help the visualization of the pairs of rents available to the incumbents in each of the regimes, it is useful

\footnotetext{
21 If each administrator could choose the local tax rate, then she would have one more instrument to maximize her rent. In period 2, she would set the tax rate to the maximum admissible level together with keeping the level of expenditure equal to zero. At the end of period 1, voters would make their decisions comparing the value-for-money of local public expenditure in the two jurisdictions (Allers 2012), namely $v_{i}=\frac{E_{i}}{\tau_{i}}$ and $v_{j}=\frac{E_{j}}{\tau_{j}}$. Accordingly, the re-election probability of incumbent $i$ would be $\rho_{i}=\frac{v_{i}}{v_{i}+v_{j}}$, and the rent would depend on $v_{i}$ and $v_{j}$ instead of $E_{i}$ and $E_{j}$. Consequently, in the presence of local tax autonomy, the expressions in (13a)-(15b) would be formulated in terms of value-for-money instead of expenditures. Of course, with two instruments, there are many combinations which can yield the same value-for-money. Our results could be interpreted as referring to a particular form of the value-for-money, in which the denominator of the ratio is standardized to one for either incumbent.
} 
Table 2 Payoff matrix

\section{Incumbent $j$}

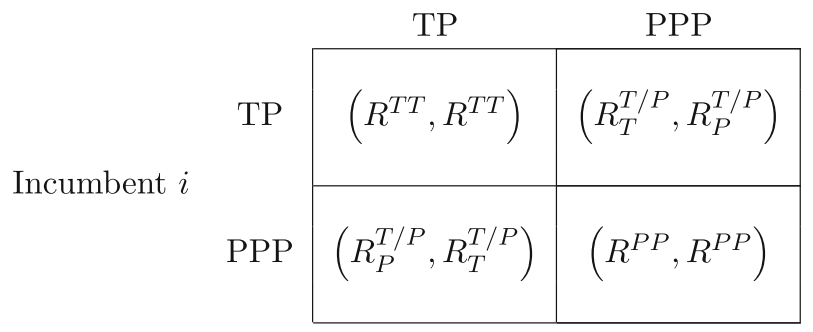

to regroup them in the payoff matrix in Table 2. In each cell of the matrix, the first payoff is the rent of the player to the left (incumbent $i$ ), the second payoff is the rent of the player to the top (incumbent $j$ ). Our goal is to identify the subgame perfect Nash equilibria of the game represented by the matrix, given the two strategies (TP and PPP) available to the incumbents.

Letting

$$
\begin{aligned}
\psi(X, K, r) & \equiv \frac{8(X-(1+r) K)^{2}}{(1+r)\left(4 X^{2}-5(1+r) K X+2(1+r)^{2} K^{2}\right)} \\
\phi(X, K, r) & \equiv \frac{8(X-(1+r) K)^{2}}{(1+r)\left(4 X^{2}-11(1+r) K X+8(1+r)^{2} K^{2}\right)}
\end{aligned}
$$

which are both non-negative, the following equivalences are found to hold:

$$
\begin{aligned}
& R^{P P}>R_{T}^{T / P} \Leftrightarrow \beta<\psi(X, K, r) \\
& R^{T T}>R_{P}^{T / P} \Leftrightarrow \beta>\phi(X, K, r) .
\end{aligned}
$$

Observing that $\phi(X, K, r) \geq \psi(X, K, r)$, we identify five cases according to the magnitude of $\beta$ for given values of the other parameters. ${ }^{22}$

Case $1 \beta<\psi(X, K, r)$ In this case, $R^{T T}<R_{P}^{T / P}$ and $R^{P P}>R_{T}^{T / P}$, hence the equilibrium of the game is (PPP, PPP). That is, although PPP grants no saving in terms of management cost relative to TP, it will be used in either jurisdiction, and the PP regime will arise.

Case $2 \beta=\psi(X, K, r)$ In this case, $R^{T T}<R_{P}^{T / P}$ and $R^{P P}=R_{T}^{T / P}$, hence the equilibria of the game are (PPP, PPP), (PPP, TP) and (TP, PPP). In the latter two

\footnotetext{
22 One can verify that $\phi(X, K, r) \geq \psi(X, K, r)$ if and only if $3 X \geq(1+r) K$, which holds as a strict inequality under the assumption that $X \geq(1+r) K$.
} 
equilibria, TP will be adopted in one jurisdiction and PPP in the other so that the T/P regime will arise.

Case $3 \psi(X, K, r)<\beta<\phi(X, K, r)$ In this case, $R^{T T}<R_{P}^{T / P}$ and $R^{P P}<R_{T}^{T / P}$ and the equilibria of the game are (PPP, TP) and (TP, PPP).

Case $4 \psi(X, K, r)<\beta=\phi(X, K, r)$ In this case, $R^{T T}=R_{P}^{T / P}$ and $R^{P P}<R_{T}^{T / P}$ and the equilibria of the game are (PPP, TP), (TP, PPP) and (TP, TP). In the latter equilibrium, TP will be used in both jurisdictions and the TT regime will arise.

Case $5 \beta>\phi(X, K, r)$ In this case, $R^{P P}<R_{T}^{T / P}$ and $R^{T T}>R_{P}^{T / P}$ so that the equilibrium of the game is (TP, TP), leading to the TT regime.

In substance, both the homogeneous regimes and the mixed regime may arise as equilibria of the game, depending on the size of the discount factor $\beta$.

The PP regime arises for sufficiently low values of $\beta$, i.e., when incumbents care relatively little about the future and point to grasping surplus up-front. Nonetheless, PPP appeals also to patient incumbents if the revenues net of the cost of management are largely above the disbursement associated with the cost of investment in period 2. To see it, consider that

$$
\lim _{X \rightarrow+\infty} \psi(X, K, r)=\lim _{X \rightarrow+\infty} \phi(X, K, r)=\frac{2}{1+r}>1 \geq \beta
$$

This tells that, with very high revenues, Case 1 will arise regardless of the weight the incumbents attach to the future. Intuitively, when $X$ is very high even in a PPP there is much surplus that can be gained in period 2, although the cost of investment must still be paid back, thus making PPP appealing also to impatient incumbents. Therefore, both administrators will have an incentive to adopt PPP.

On the opposite, the TT regime arises for high values of $\beta$, i.e., when incumbents are patient and care of being re-elected to extract surplus in the second period essentially. Nonetheless, also impatient incumbents will prefer to choose TP, if the net revenues are close to the disbursement, which should be made under PPP to pay back the cost of investment in period 2 . This can be viewed by computing

$$
\lim _{X \rightarrow(1+r) K} \psi(X, K, r)=\lim _{X \rightarrow(1+r) K} \phi(X, K, r)=0<\beta,
$$

which shows that, with very low revenues, Case 5 will arise regardless of the weight the incumbents attach to the future. To see the intuition behind this finding, suppose that the incumbents consider using PPP. Because, with $X$ very low, there is nothing to gain in period 2 under PPP, one administrator will want to switch from PPP to TP in the attempt to appropriate a higher rent (since $R_{T}^{T / P}>R^{P P}$ ). But then the same strategy will be convenient to the other administrator as well (since $R^{T T}>R_{P}^{T / P}$ ). As a result, they will both end up using TP.

Lastly, the T/P regime arises for intermediate values of $\beta$, provided that the revenues less the cost of management are moderately above the disbursement which is required to pay back the cost of investment in period 2 if PPP is used. With PPP granting 
a contained surplus in the second period, this is a case where its use is moderately appealing to the administrators. Hence, they will not both insist on PPP. One of the two will rather switch to TP. Given the election rule, it pays off for both incumbents to specialize as rent-takers in different periods. The incumbent who chooses PPP goes for the first-period rent and leaves re-election for the other incumbent, who chooses $\mathrm{TP}$ and takes the second-period rent $\left(R_{T}^{T / P}>R^{P P}\right.$ and $\left.R_{P}^{T / P}>R^{T T}\right)$.

\subsection{Discussion}

Our analysis highlights that there are essentially two situations in which one should be concerned with a strategic use of PPP in environments where that choice would not be backed by an efficiency rationale.

First, one should expect to see a pronounced use of PPP when jurisdictions have a substantial capability of raising resources through taxation and/or projects are highly lucrative ( $\Gamma$ is high, hence Case 1 is likely to be the relevant one). Because important rents are available in those contexts, administrators will all prefer to use the contractual solution that permits to extract more of those rents (and more rapidly). That solution is given by PPP. Indeed, it was found that $R^{P P}>R^{T T}$ since the cost of investment is partially collectivized under PPP, whereas it only burdens administrators under TP. This result is in line with the observation that municipalities rely recurrently on PPP to undertake big projects, notably in energy, transportation, water, and ICT sectors, and that PPP arrangements are primarily adopted when (local) governments are maximizing up-front benefits seeking rents. ${ }^{23}$ Noticeably, absent any revenue disparities, successful rent extraction does not prevent yardstick competition from being effective, as was found in the analysis of the PP regime.

Second, one should expect to see only a limited dissemination of PPP when jurisdictions have a moderate fiscal/revenue capacity and/or projects are mildly lucrative $(\Gamma$ takes intermediate values, hence Case 3 is likely to be the relevant one). With less surplus being available in those situations, the best way for administrators to extract more of it is to differentiate their strategies by choosing different contractual arrangements. Therefore, in addition to administrators who follow a short-term strategy, using PPP to appropriate much of the available surplus up-front, with little interest in a second mandate, there will also be administrators who follow a longer-term strategy, using TP to extract surplus over time, hence caring more of a second mandate. This result is consistent with the observation that, in general, moderately rich municipalities make only some use of PPP and undertake moderately profitable projects, such as sport arenas and entertainment facilities. ${ }^{24}$ Importantly, because by differentiating their choices of

\footnotetext{
23 See, for instance, Cunha Marques and Berg (2011) on a case of Portuguese municipalities.

24 According to the data reported by Ufficio Valutazione Impatto. Senato della Repubblica (2018), whereas $100 \%$ of the Italian municipalities with more than 20000 residents have used PPP at least once over the period 2002-2016, this is only the case of $40 \%$ of the municipalities with less than 2000 residents and $68 \%$ of the municipalities with 2000-5000 residents. The biggest and most profitable projects are concentrated in Rome, Milan and a few other big cities. Of course, one cannot exclude the possibility of this observation also capturing the administrators' attempt to take advantage of externalities existing between project phases, which are ruled out in the final part of our analysis. We yet offer an additional reason potentially underlying that observation.
} 
project governance incumbents are able to weaken the competitive pressure, yardstick competition is hindered even if jurisdictions are alike in terms of revenue capacity.

\section{Conclusions}

Political yardstick competition is deemed to help voters infer the effort made by local administrators to pursue social interests. By comparing the level of public services provided by their own incumbent with that of similar jurisdictions, voters can re-elect good politicians and send non-performers packing, thus giving administrators incentives to a better performance. Whereas it is now well known that this mechanism may nonetheless be biased when jurisdictions display fiscal disparities that voters do not perceive correctly, our study highlighted that the effectiveness of political yardstick competition may also be hindered when pure rent-seeking administrators use different financing (and organizational) forms to develop similar public infrastructure projects. Provided different financing forms are associated with different inter-temporal disbursement profiles, the administrators' reaction functions exhibit asymmetric slopes. Unusual in models of symmetric yardstick competition, this difference in slope, which results from the decisions made by the administrators, translates into asymmetric reelection probabilities and rents. By taking an institutional perspective on the TP/PPP dichotomy, we could thus clarify how the use of different forms of public project governance may help opportunistic administrators pursue private interests, given their strategic interactions in the political arena. The main takeaway of our analysis is that PPP represents a potentially good instrument for rent-seeking politicians to exploit unsophisticated voters who do not look forward. In such contexts, politicians can thus be expected to use this instrument all the more if they are impatient, or if there are plenty of resources that can be extracted out of that. All in all, yardstick competition fares well as long as it is based on simple information such as the experienced level of public services. It may be biased in contexts in which political incumbents attempt to deliberately increase the complexity of the terms of comparison, for instance, by adopting different financing forms to develop otherwise identical public projects. A possible remedy to attenuate this issue could be to impose more standardization in public contracting at the sub-national level in order to both limit the administrators' discretion and make information more readable to citizens.

There are a number of alleys to further research.

First, the analysis could be extended to allow for the functional form of the reelection probability to differ under the two contractual forms. This hypothesis is backed by recent studies, which suggest that the attitude of citizens towards the involvement of private finance in public projects may abstract from efficiency considerations and rather reflect ideological factors, at least to some extent. Particularly, the more familiar that citizens are with PPPs, the more likely that they will be to welcome their use in new projects (Boyer and Slyke 2019).

Second, we took the undertaking and completion of the project as given and allowed the local administrators to decide on its specific governance. It would be interesting to also endogenise the decision to undertake or not the project and, in addition, to let the completion of the project occur after the term limit so that the service is not 
available for use until after the next administrator will be in office. On the one hand, the possibility of the benefits of the project being delayed to future administrations might hinder the current administrators' interest in the project. On the other hand, the very fact of launching a new project, together with the choice of a convenient financing form, also accounting for the complexity of the project, the availability of internal competences, and the possibility of risk sharing, might raise the probability of the incumbents to be re-elected within the term limit and boost their ability to extract rents. Examining this environment is on our research agenda.

Lastly, we considered jurisdictions which are perfectly alike as to their tax bases and tax revenues, but may decide to set different expenditures. We would like to look at jurisdictions which, while having equal fiscal capacities, are characterized by different compositions of the aggregate tax bases (properties, incomes, tourists).

Acknowledgements We owe thoughtful suggestions to David Martimort and Antonio Nicolò. We also thank Alfons Weichenrieder for his comments as well as seminar participants at Université de Caen Normandie and audiences in the 2019 EPCS Meeting (Jerusalem), the 2019 CESifo Conference on Public Sector Economics (Munich), and the CRIEP 20th Anniversary Workshop "Research frontiers on PPPs" (Padua). The usual disclaimer applies.

Funding Open access funding provided by Università degli Studi di Bari Aldo Moro within the CRUICARE Agreement.

Open Access This article is licensed under a Creative Commons Attribution 4.0 International License, which permits use, sharing, adaptation, distribution and reproduction in any medium or format, as long as you give appropriate credit to the original author(s) and the source, provide a link to the Creative Commons licence, and indicate if changes were made. The images or other third party material in this article are included in the article's Creative Commons licence, unless indicated otherwise in a credit line to the material. If material is not included in the article's Creative Commons licence and your intended use is not permitted by statutory regulation or exceeds the permitted use, you will need to obtain permission directly from the copyright holder. To view a copy of this licence, visit http://creativecommons.org/licenses/by/4.0/.

\section{A Characterization of the equilibria}

\section{A.1 The TT regime}

Concavity of the problem To verify concavity, we compute the second derivative of (1) with respect to $E_{i}$ and we check that it is negative. Indeed, we have

$$
-2 \beta \frac{E_{j}}{\left(E_{i}+E_{j}\right)^{3}}\left(\Gamma-C_{T}\right)<0 .
$$

Derivation of (4) The equilibrium levels of expenditure are found by solving the following system of reaction functions:

$$
\begin{aligned}
& E_{i}\left(E_{j}\right)=\sqrt{\beta\left(\Gamma-C_{T}\right) E_{j}}-E_{j} \\
& E_{j}\left(E_{i}\right)=\sqrt{\beta\left(\Gamma-C_{T}\right) E_{i}}-E_{i},
\end{aligned}
$$


where $\Gamma-C>0$. Rewriting the former as

$$
E_{i}+E_{j}=\sqrt{\beta\left(\Gamma-C_{T}\right) E_{j}}
$$

and taking squares of both sides to remove the square root, we obtain

$$
E_{i}^{2}+E_{j}^{2}=\left(\beta\left(\Gamma-C_{T}\right)-2 E_{i}\right) E_{j}
$$

One solution to this equation is $E_{i}=E_{j}=0$. To find the other solution, replace $E_{j}$ from the second reaction function. It yields

$$
\sqrt{\beta\left(\Gamma-C_{T}\right) E_{i}}=\sqrt{\beta\left(\Gamma-C_{T}\right) \sqrt{\beta\left(\Gamma-C_{T}\right) E_{i}}-\beta\left(\Gamma-C_{T}\right) E_{i}} .
$$

Taking squares of both sides, we further get

$$
E_{i}=\frac{1}{2} \sqrt{\beta\left(\Gamma-C_{T}\right) E_{i}}
$$

and so

$$
E_{i}^{T T}=\frac{\beta}{4}\left(\Gamma-C_{T}\right)
$$

Replacing this expression in $E_{j}\left(E_{i}\right)$ we obtain

$$
\begin{aligned}
E_{j}^{T T} & =\sqrt{\beta\left(\Gamma-C_{T}\right) \frac{\beta}{4}\left(\Gamma-C_{T}\right)}-\frac{\beta}{4}\left(\Gamma-C_{T}\right) \\
& =\frac{\beta}{2}\left(\Gamma-C_{T}\right)-\frac{\beta}{4}\left(\Gamma-C_{T}\right) \\
& =\frac{\beta}{4}\left(\Gamma-C_{T}\right)
\end{aligned}
$$

Hence, (4) is found.

Derivation of (5) Replacing (4) in the probability function yields

$$
\rho_{i}^{T T}=\frac{\left(\Gamma-C_{T}\right)^{2}\left(\Gamma-C_{T}\right)}{\left(\Gamma-C_{T}\right)^{2}\left(\Gamma-C_{T}\right)+\left(\Gamma-C_{T}\right)^{2}\left(\Gamma-C_{T}\right)},
$$

which is easily simplified to obtain (5).

Derivation of (6) Replacing (4) in (1) yields

$$
R_{i}^{T T}=\Upsilon-\frac{\beta}{4}\left(\Gamma-C_{T}\right)-K+\frac{\beta}{2}\left(\Gamma-C_{T}\right)
$$

so that (6) is found. 


\section{A.2 The PP regime}

Concavity of the problem To verify concavity, we compute the second derivative of (7) with respect to $E_{i}$ and we check that it is negative. Indeed, we have

$$
-2 \beta \frac{E_{j}}{\left(E_{i}+E_{j}\right)^{3}}\left(\Gamma-(1+r) K-C_{P}\right)<0 .
$$

Derivation of (10) The equilibrium levels of expenditure are found by solving the following system of reaction functions:

$$
\begin{aligned}
& E_{i}\left(E_{j}\right)=\sqrt{\beta\left(\Gamma-(1+r) K-C_{P}\right) E_{j}}-E_{j} \\
& E_{j}\left(E_{i}\right)=\sqrt{\beta\left(\Gamma-(1+r) K-C_{P}\right) E_{i}}-E_{i},
\end{aligned}
$$

where $\Gamma-(1+r) K-C_{P}>0$. Rewriting the former as

$$
E_{i}+E_{j}=\sqrt{\beta\left(\Gamma-(1+r) K-C_{P}\right) E_{j}}
$$

and taking squares of both sides to remove the square root, we obtain

$$
E_{i}^{2}+E_{j}^{2}+2 E_{i} E_{j}=\beta\left(\Gamma-(1+r) K-C_{P}\right) E_{j}
$$

One solution to this equation is $E_{i}=E_{j}=0$. To find the other solution, replace $E_{j}$ from the second reaction function. It yields

$$
\begin{aligned}
& \left(\sqrt{\beta\left(\Gamma-(1+r) K-C_{P}\right) E_{i}}-E_{i}\right)^{2}+2 E_{i} \sqrt{\beta\left(\Gamma-(1+r) K-C_{P}\right) E_{i}}-E_{i}^{2} \\
& =\beta\left(\Gamma-(1+r) K-C_{P}\right)\left(\sqrt{\beta\left[\Gamma-(1+r) K-C_{P}\right] E_{i}}-E_{i}\right)
\end{aligned}
$$

which is rearranged as

$2 E_{i}\left(\Gamma-(1+r) K-C_{P}\right)=\left(\Gamma-(1+r) K-C_{P}\right) \sqrt{\beta\left(\Gamma-(1+r) K-C_{P}\right) E_{i}}$.

Simplifying and taking squares of both sides we further obtain

$$
E_{i}^{P P}=\frac{\beta}{4}\left(\Gamma-(1+r) K-C_{P}\right) .
$$

Replacing this expression in $E_{j}\left(E_{i}\right)$ we get

$$
E_{j}^{P P}=\beta \sqrt{\frac{\left(\Gamma-(1+r) K-C_{P}\right)^{2}\left(\Gamma-(1+r) K-C_{P}\right)^{2}}{4\left(\Gamma-(1+r) K-C_{P}\right)^{2}}} .
$$


Hence, (10) is found.

Derivation of (11) Replacing (10) in the probability function yields

$$
\rho_{i}^{P P}=\frac{\frac{\Gamma-(1+r) K-C_{P}}{4}}{\frac{\Gamma-(1+r) K-C_{P}}{4}+\frac{\Gamma-(1+r) K-C_{P}}{4}}
$$

so that (11) is found.

Derivation of (12) Replacing (10) and (11) in (7) yields

$$
R_{i}^{P P}=\Upsilon-\beta \frac{\Gamma-(1+r) K-C_{P}}{4}+\beta \frac{\Gamma-(1+r) K-C_{P}}{2}
$$

so that (12) is found.

\section{A.3 The T/P regime}

Concavity of the problem of incumbent $P$ The concavity of the problem of incumbent $T$ was verified with regards to the TT regime. We now verify the concavity of the problem of incumbent $P$. Indeed, we have

$$
-2 \beta \frac{E_{T}}{\left(E_{T}+E_{P}\right)^{3}}\left(\Gamma-(1+r) K-C_{P}\right)<0 .
$$

Derivation of (13a) and (13b) The equilibrium levels of expenditure are found by solving (3) and (9). Rewriting the former as

$$
E_{T}^{2}+E_{P}^{2}=\left(\beta\left(\Gamma-C_{T}\right)-2 E_{T}\right) E_{P}
$$

we again see that one solution is $E_{T}=E_{P}=0$. To find the other solution, we replace $E_{P}$ from the second reaction function and obtain

$$
E_{T}(2 \Gamma-(1+r) K-C)=(\Gamma-C) \sqrt{\beta E_{T}\left(\Gamma-(1+r) K-C_{P}\right)} .
$$

Taking squares of both sides and rearranging, (13a) is derived. Replacing in (9), one also finds

$$
E_{P}^{T / P}=\beta\left(\frac{\left(\Gamma-C_{T}\right)\left(\Gamma-(1+r) K-C_{P}\right)}{2 \Gamma-(1+r) K-C}-\frac{\left(\Gamma-(1+r) K-C_{P}\right)\left(\Gamma-C_{T}\right)^{2}}{(2 \Gamma-(1+r) K-C)^{2}}\right)
$$


Rearranging, (13b) is obtained.

Derivation of (14a) and (14b) Replacing (13a) and (13b) in the probability function of administrator $T$ yields

$$
\begin{aligned}
\rho_{T}^{T / P} & =\frac{\beta \frac{\left(\Gamma-(1+r) K-C_{P}\right)\left(\Gamma-C_{T}\right)^{2}}{(2 \Gamma-(1+r) K-C)^{2}}}{\beta \frac{\left(\Gamma-(1+r) K-C_{P}\right)\left(\Gamma-C_{T}\right)^{2}}{(2 \Gamma-(1+r) K-C)^{2}}+\beta \frac{\left(\Gamma-(1+r) K-C_{P}\right)^{2}\left(\Gamma-C_{T}\right)}{(2 \Gamma-(1+r) K-C)^{2}}} \\
& =\frac{\left(\Gamma-(1+r) K-C_{P}\right)\left(\Gamma-C_{T}\right)^{2}}{\left(\Gamma-(1+r) K-C_{P}\right)\left(\Gamma-C_{T}\right)^{2}+\left(\Gamma-(1+r) K-C_{P}\right)^{2}\left(\Gamma-C_{T}\right)},
\end{aligned}
$$

from which (14a) is derived. Replacing (13a) and (13b) in the probability function of administrator $P$ yields

$$
\begin{aligned}
\rho_{P}^{T / P} & =\frac{\beta \frac{\left(\Gamma-(1+r) K-C_{P}\right)^{2}\left(\Gamma-C_{T}\right)}{(2 \Gamma-(1+r) K-C)^{2}}}{\beta \frac{\left(\Gamma-(1+r) K-C_{P}\right)^{2}\left(\Gamma-C_{T}\right)}{(2 \Gamma-(1+r) K-C)^{2}}+\beta \frac{\left(\Gamma-(1+r) K-C_{P}\right)\left(\Gamma-C_{T}\right)^{2}}{(2 \Gamma-(1+r) K-C)^{2}}} \\
& =\frac{\left(\Gamma-(1+r) K-C_{P}\right)^{2}\left(\Gamma-C_{T}\right)}{\left(\Gamma-(1+r) K-C_{P}\right)^{2}\left(\Gamma-C_{T}\right)+\left(\Gamma-(1+r) K-C_{P}\right)\left(\Gamma-C_{T}\right)^{2}},
\end{aligned}
$$

from which (14b) is derived.

Derivation of (15a) and (15b) Replacing (13a) and (13b) in (1 ) yields

$$
\begin{aligned}
R_{T}^{T / P} & =\Upsilon-\beta \frac{\left(\Gamma-(1+r) K-C_{P}\right)\left(\Gamma-C_{T}\right)^{2}}{(2 \Gamma-(1+r) K-C)^{2}}-K+\frac{\beta\left(\Gamma-C_{T}\right)^{2}}{2 \Upsilon+F-(1+r) K-C} \\
& =\Upsilon-K+\frac{\beta\left(\Upsilon+F_{T}-C_{T}\right)^{2}}{2 \Gamma-(1+r) K-C}\left(1-\frac{\Gamma-(1+r) K-C_{P}}{2 \Gamma-(1+r) K-C}\right),
\end{aligned}
$$

from which (15a) is derived. Replacing (13a) and (13b) in (7) yields

$$
\begin{aligned}
R_{P}^{T / P} & =\Upsilon-\beta\left(\Gamma-C_{T}\right) \frac{\left(\Gamma-(1+r) K-C_{P}\right)^{2}}{(2 \Gamma-(1+r) K-C)^{2}}+\beta \frac{\left(\Gamma-(1+r) K-C_{P}\right)^{2}}{2 \Upsilon+F-(1+r) K-C} \\
& =\Upsilon+\beta \frac{\left(\Gamma-(1+r) K-C_{P}\right)^{2}}{2 \Gamma-(1+r) K-C}\left(1-\frac{\Gamma-C_{T}}{2 \Gamma-(1+r) K-C}\right),
\end{aligned}
$$

from which $(15 b)$ is derived.

\section{References}

Allain-Dupré D (2011) Multi-level Governance of public investment: lessons from the crisis. OECD Regional Development Working Papers, 2011/05, OECD Publishing. https://doi.org/10.1787/ $5 \mathrm{~kg} 87 \mathrm{n} 3 \mathrm{bp} 6 \mathrm{jb}$-en

Allers MA (2012) Yardstick competition, fiscal disparities, and equalization. Econ Lett 117:4-6 
Antellini Russo F, Zampino R (2010) Machiavellian PPP? Evidence from Italian Local Government's Projects for Public Services. Technical report, IV International Public Procurement Conference Proceedings, pp 774-776

Bennett J, Iossa E (2006) Building and managing facilities for public services. J Public Econ 90(10):21432160

Besley T, Case A (1995) Incumbent behavior: vote seeking, tax setting and yardstick competition. Am Econ Rev 85:25-45

Bodenstein M, Ursprung HW (2005) Political yardstick competition, economic integration, and constitutional choice in a federation: a numerical analysis of a contest success function model. Public Choice 124:329-352

Bordignon M, Cerniglia F, Revelli F (2003) In search of yardstick competition: a spatial analysis of Italian municipality property tax setting. J Urban Econ 54(2):199-217

Boyer EJ, Slyke DMV (2019) Citizen attitudes towards public-private partnerships. Am Rev Public Adm 49(3):259-274

Buettner T, von Schwerin A (2016) Yardstick competition and partial coordination: Exploring the empirical distribution of local business tax rates. J Econ Behav Organ 124:178-201

Buso M, Marty F, Tran PT (2017) Public-private partnerships from budget constraints: looking for debt hiding? Int J Ind Organ 51:56-84

Cole MT, Pastine I, Pastine T (2018) Incumbency advantage in an electoral contest. Econ Soc Rev 49(4):419_ 436

Cunha Marques R, Berg S (2011) Public-private partnership contracts: a tale of two cities with different contractual arrangements. Public Adm 89(4):1585-1603

Danau D, Vinella A (2015) Public-private contracting under limited commitment. J Public Econ Theory 17(1):78-110

Danau D, Vinella A (2017) From fixed to state-dependent duration in public-private partnerships. J Econ Manag Strategy 26(3):636-660

Di Liddo G, Giuranno M (2016) Asymmetric yardstick competition and municipal cooperation. Econ Lett 141:64-66

Di Liddo G, Morone A (2017) Yardstick competition and fiscal disparities: an experimental study. Econ Lett 159:134-137

Engel E, Fischer R, Galetovic A (2011) Public-private partnerships to revamp US infrastructures. The Hamilton Project. Discussion Paper 2011/02. Brookings

Epstein GS, Nitzan S (2006) The politics of randomness. Soc Choice Welf 27(2):423-433

Hart O (2003) Incomplete contracts and public ownership: Remarks, and an application to public-private partnerships. Econ J 113(486):C69-C76

HM Treasury (2006) PFI: strengthening long-term partnerships. Her Majesty's Treasury Technical report

Huang Y, He M (2021) Structural analysis of Tullock contests with an application to U.S. house of representatives elections. Int Econ Rev. https://doi.org/10.1111/iere.12502

Iossa E, Martimort D (2016) Corruption in PPPs, incentives and contract incompleteness. Int J Ind Organ 44:85-100

Iossa E, Saussier S (2018) Public private partnerships in Europe for building and managing public infrastructures: an economic perspective. Ann Public Cooperative Econ 89(1):25-48

Jia H, Skaperdas S, Vaidya S (2013) Contest functions: Theoretical foundations and issues in estimation. Int J Ind Organ 31(3):211-222

Klumpp T, Konrad K, Solomon A (2019) The dynamics of majoritarian blotto games. Games Econ Behav 117:402-419

Kotsogiannis C, Schwager R (2008) Accountability and fiscal equalization. J Public Econ 92(12):2336-2349

Long NV (2013) The theory of contests: a unified model and review of the literature. Eur J Polit Econ 32:161-181

Martimort D, Pouyet J (2008) To build or not to build: normative and positive theories of public-private partnerships. Int J Ind Organ 26(2):393-411

Maskin E, Tirole J (2008) Public-private partnerships and government spending limits. Int J Ind Organ 26(2):412-420

Pastine I, Pastine T (2012) Incumbency advantage and political campaign spending limits. J Public Econ 96(1):20-32

Tran PT, Klien M (2017) Public private partnerships as innovation adoption: Does the process count? Acad Manag Proc. https://doi.org/10.5465/AMBPP.2017.16191abstract 
Tullock G (1980) Efficient rent seeking. In: Buchanan J, Tollison R, Tullock G (eds) Toward a theory of rent seeking society. Texas A\&M University Press, Oxford, pp 97-112

Ufficio Valutazione Impatto. Senato della Repubblica (2018) I comuni italiani e il Partenariato Pubblico Privato. Documento di analisi no. 15

Publisher's Note Springer Nature remains neutral with regard to jurisdictional claims in published maps and institutional affiliations. 